\title{
Community-based responses to climate hazards: typology and global analysis
}

\author{
Barbara Paterson $^{1}$ (D) - Anthony Charles ${ }^{1}$
}

Received: 1 December 2017 / Accepted: 3 December 2018 / Published online: 10 January 2019

(C) The Author(s) 2019

\begin{abstract}
The severity and frequency of climate change hazards are increasing around the world. Because the impacts are most acutely felt in local communities, it is critical to improve understanding of the response options that are available for and being chosen by communities. We conducted a mixed methods analysis of case studies reporting community-based responses to climate change hazards. Based on content analysis of published case studies, we generated an emergent evidence-based typology of such responses according to their nature and goals. Using this typology, we quantitatively analysed more than 1500 response examples and determined the patterns with which community-level climate change adaptation and disaster mitigation strategies vary across world regions and across economic and governance conditions. Specifically, diversity of responses is lower in developing countries, and implementation of local-level policy and planning responses is less frequent in countries characterised by low governance quality. Our results confirm that, although there is much that local communities can do to respond to the challenges of climate change, there is also a need for increased support of local activities. By synthesising data from many local studies, our research provides a first global evidence base for local-level climate change adaptation policy.
\end{abstract}

\section{Introduction: local-level responses to climate change hazards}

The effects of climate change are most acutely felt at the local level (Cutter et al. 2012), through a range of hazards - such as droughts (Trenberth et al. 2014), flood risks, (Hirabayashi et al. 2013; Jongman et al. 2012) and associated losses (Hallegatte et al. 2013) - which are expected to increase in frequency and severity (IPCC 2014a). Already,

Electronic supplementary material The online version of this article (https://doi.org/10.1007/s10584-0182345-5) contains supplementary material, which is available to authorized users.

Barbara Paterson

Barbara.Paterson@smu.ca

1 School of the Environment and School of Business, Saint Mary's University, Halifax, Nova Scotia B3H 3C3, Canada 
over the two-decade period 1995-2015, weather-related hazards - with potential links to climate change - caused 6457 disasters globally which claimed 606,000 lives and affected on average 205 million people annually (CRED 2015). Although attention to climate change adaptation is increasing across the globe, implementation remains limited especially at the local or place-based community level (IPCC 2014b).

While it is typically premised that local communities have no control over the occurrence or magnitude of a hazard, nonetheless, there are many measures available to mitigate against hazards (Day and Fearnley 2015). Communities, and governments, influence the ultimate consequences of hazards through their choice of responses (Cutter et al. 2012). Such responses aim to reduce negative effects of hazards, protect assets, and help people to escape from exposure to extreme conditions. How communities choose to respond constitutes a 'response portfolio' that may cover multiple types of response, across multiple temporal scales - for example, with short-term emergency responses after severe flooding accompanied by longer-term strategies anticipating future floods and taking action to be prepared.

With multilateral agencies, national governments and non-government agencies increasingly taking interest in community-based efforts (Reid and Huq 2014), policy decisions about advisory and financing services are needed at a higher than local level. Thus, more integrated hazard response knowledge is needed to guide policy and practice (Cutter et al. 2015) in addressing hazards at multiple scales (Fekete et al. 2010).

The growing literature on local responses to hazards (Rojas Blanco 2006; Dekens 2007; Prabhakar et al. 2009; Reid et al. 2009; Adger et al. 2013; Lei et al. 2014) includes qualitative case studies outlining efforts by individual communities to cope with hazards (Ferdinand et al. 2012; Alam and Rahman 2014; McNamara and Prasad 2014). However, these need to be compiled and synthesised to produce a global picture of local-level activities to address climate change impacts. Such an analysis will help to overcome (1) fragmentation into different disciplines, and (2) a focus on single types of hazards or individual aspects of the problem (Cutter et al. 2015; Henly-Shepard et al. 2015; Adger et al. 2013). The need, then, is for a global database of community-based hazard interventions, to be able to assess how communities are responding to climate change hazards. The aim of this study is to meet this need.

We do so by drawing a set of case studies of community hazard responses from the available literature, examining published case studies that describe responses to rapid events (such as a sudden flood or storm) or the ongoing effects of long-term threats (e.g. sea level rise or erosion) on the spatial scale of a place-based community, i.e. within a reasonably small and well-defined geographic space such as a village, neighbourhood or small city. We are interested in actual response actions, recognising that interventions at the local level can differ from community adaptation strategies that are recommended by researchers and policy makers (Savo et al. 2017).

To our knowledge this is the first study of its kind. The results provide a capability to examine how reported community responses to climate change hazards vary by hazard type, world region and corresponding national economic and governance conditions. Our mixed methods analysis connects the data from many local studies to the regional and global scales of hazard management and disaster mitigation. Such knowledge about what communities already are and are not doing to respond to hazards is crucial for developing global, national and local strategies to increase community resilience (Berkes and Ross 2013) to climate change. 


\section{Data and methods}

We extracted information from 127 peer-reviewed journal articles and compiled a global data set of 1684 records of reported community-based response actions to 349 different hazard events (Table 1). To identify the articles, we conducted a systematic review following EPPI (Evidence for Policy and Practice Information) Center guidelines (Gough et al. 2012). Papers were eligible for inclusion if they reported on both the following criteria: (i) a hazardous event (a climate-related event or trend that has caused loss of life or health impacts or damage or loss to property, infrastructure, livelihoods and environmental resources); and (ii) a community (a specific local-level geographic area, e.g. a village or group of villages, a municipality, a small city or a neighbourhood). Papers were excluded if they (1) did not cite a specific event or geographic location; (2) described only potential but not actual actions; (3) provided assessments of risks, impact or vulnerability but no response actions; or (4) described results from modelling exercises.

Literature searches were conducted with the help of a librarian. We searched nine databases: Abstracts in Anthropology, ALJC, Annual Reviews, EBSCO Academic, GEOBASE, GeoRef, Greenfile, JSTOR and ScienceDirect. Search terms varied slightly between databases and included (hazard OR storm OR hurricane OR cyclone OR earthquake OR flood ... ) AND 'communit*'. Bibliographies of relevant papers were screened. Only English language peerreviewed articles were included in the database. This has obvious limitations, such as omitting papers published in other languages, and the entire grey literature. However, the results here provide a unique starting point for further analyses, which might include a broader range of literature. Alternatively, other data collection methods could be considered, such as having each national government contribute cases from within that country, although it would be challenging to ensure that the database is compiled using a common methodology in all countries.

We used conventional content analysis (Krippendorff 2013) to extract the following qualitative information from each article: the hazardous event (type of hazard, year, location, description or context), the geographic location (name or description of the community, country) and description of the response action. The data was collated into a relational database.

Hazard events were grouped into four categories based on the Em-Dat (CRED 2011) classification of natural disasters (Table 2). Geophysical hazards, such as earthquakes (including tsunamis) and hazards resulting from volcanic activity are not typically associated with climate change and were therefore excluded from the analysis. We did, however, include landslide as a sub-type of geophysical hazard that is associated with climate change (Gariano and Guzzetti 2016; Seneviratne et al. 2012).

The analysis here is based on defining 'hazard events' and 'response events'. Each of these is defined by three variables: location (community), year (or other specific time period) and type of hazard. As a result, most articles resulted in multiple records in the database, since each one may well involve multiple communities, multiple times and multiple hazard types. In terms of hazard events, if an article reports that the same hurricane affected two communities, two hazard events were extracted. Similarly, if two hurricanes hit a particular community, at different times, or if two different hazards (e.g. a hurricane and a flood) affect a community in the same time period, each would involve two hazard events. Turning to response events, if an article reports the same response for several communities, each of these examples was included as a record in the database. Similarly, if multiple evacuations were reported for the 


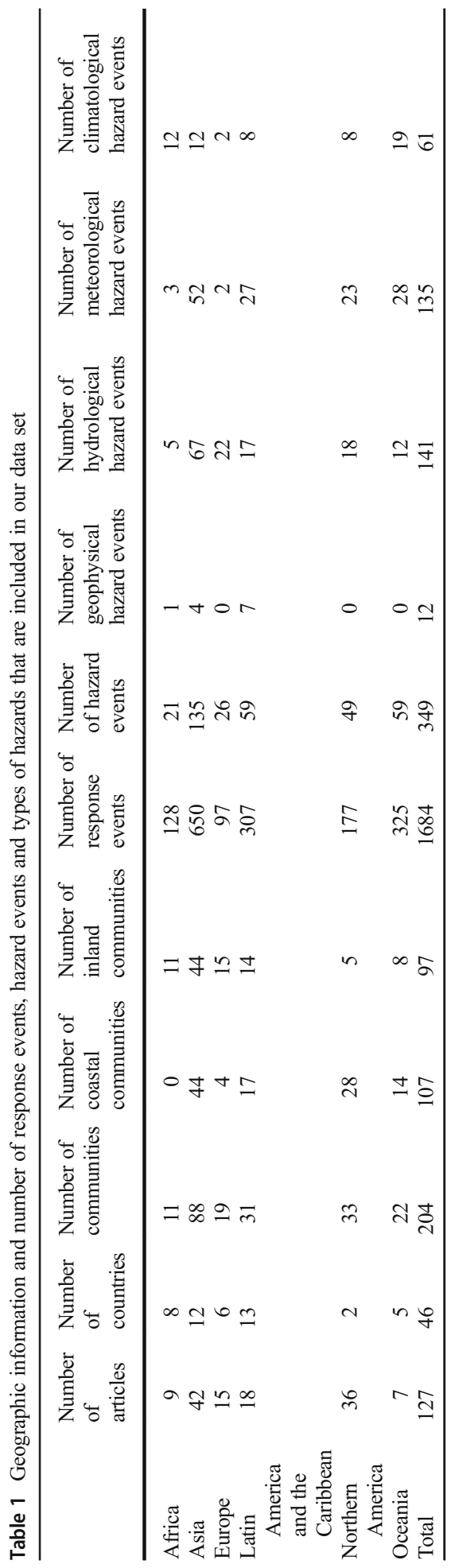


Table 2 Number of reported events that were included in the analysis by hazard category $(n=349)$

\begin{tabular}{|c|c|c|c|}
\hline Geophysical (12) & Hydrological (147) & Meteorological (135) & Climatological (61) \\
\hline \multicolumn{4}{|l|}{ Continuous (85) } \\
\hline & Erosion (18) & & Climate variability (7) \\
\hline & Saltwater intrusion (4) & & Drought (44) \\
\hline & Sea level rise (2) & & Environmental change (10) \\
\hline \multicolumn{4}{|l|}{ Rapid (246) } \\
\hline & Flood (111) & Storm (109) & \\
\hline & & Extreme weather (26) & \\
\hline \multicolumn{4}{|l|}{ Sudden (24) } \\
\hline Mass movement (dry) (12) & Flow or slide (wet) (12) & & \\
\hline
\end{tabular}

Hazard categories are based on the Em-Dat general classification of disasters (http://www.emdat.be/classification)

same community following separate hazard events, each evacuation was included as a separate response action. Finally, all response actions reported in a given article were extracted irrespective of the particular response, or hazard, that is the focus of the paper. For instance, if a paper that is primarily about migration as a response to extreme weather also mentions that community members changed insurance policies to cover damage from flooding, both examples were included in the database as separate records.

As a result of the above method, one article yielded on average information about 2.8 hazard events and 13.3 response examples (Table 1); thus, in many cases, the content analysis extracted more data from the articles than the title or abstract might suggest. Each article provided a different quantity of data points for our analysis depending on the time period covered and the richness of the descriptions.

The response typology was developed through a grounded theory (Strauss and Corbin 1998) process. The descriptions of response actions represent first level or open codes, i.e. in each article the sentences or paragraphs discussing a particular response action were labelled, resulting in 899 codes. Categories of response actions were developed through second level or substantive codes that group similar responses. Third level, theoretical codes were developed by examining the second level codes and the relationships between them. This process resulted in 15 types that fall within five classes of response actions.

We then examined the frequencies of reported actions for each hazard event and response class by geographic Sub-region (using United Nations groupings), Gross National Income (GNI) and World Governance Indicator (WGI). We determined sets of relative frequencies of all response classes (hereafter called the 'response portfolios') grouping countries by geographic sub-region, GNI and WGI. We then calculated a Gini coefficient for each group to measure the distribution of response examples across response classes, excluding groups with less than 10 data points (Table 3). This analysis was based on the idea that greater diversity of hazard responses may be considered beneficial for community resilience to climate change,

Gross National Income data were taken from the 2015 Human Development Report (UNDP 2015) dataset. Countries were coded according to World Bank categories for the fiscal year 2017 as low income (Low GNI=1) if GNI per capita is below USD 4035 (combining low and low middle-income countries), as medium income (Mid GNI $=2$ ) if GNI is between USD 4036 and USD 12,475 and as high income (High GNI=3) if GNI is above USD 12,475 .

We aggregated available World Bank governance indicators (Kaufmann and Kraay 2017) for each country using arithmetic means. The resulting aggregate index expresses governance 
Table 3 Number of response examples and distribution across response classes as expressed by a Gini coefficient by geographic sub-region

\begin{tabular}{|c|c|c|c|c|}
\hline World region & Sub-region & $\begin{array}{l}\text { Number of response } \\
\text { events }\end{array}$ & $\begin{array}{l}\text { Distribution across response } \\
\text { classes }\end{array}$ & Gini \\
\hline \multirow[t]{4}{*}{ Africa } & Eastern Africa & 96 & Highly unequal & 0.71 \\
\hline & Northern Africa & 2 & Insufficient data & \\
\hline & Southern Africa & 12 & Equal & 0.47 \\
\hline & Western Africa & 18 & Equal & 0.46 \\
\hline \multirow[t]{6}{*}{ Asia } & Central Asia & & No data & \\
\hline & Eastern Asia & 29 & Equal & 0.42 \\
\hline & North-Eastern Asia & & No data & \\
\hline & South-Eastern Asia & 112 & Highly equal & 0.29 \\
\hline & Southern Asia & 509 & Unequal & 0.49 \\
\hline & Western Asia & & No data & \\
\hline \multirow[t]{4}{*}{ Europe } & Eastern Europe & & No data & \\
\hline & Northern Europe & 48 & Highly equal & 0.35 \\
\hline & Southern Europe & 44 & Unequal & 0.49 \\
\hline & Western Europe & 5 & Insufficient data & \\
\hline \multirow{3}{*}{$\begin{array}{l}\text { Latin America and the } \\
\text { Caribbean }\end{array}$} & Caribbean & 199 & Unequal & 0.53 \\
\hline & Central America & 87 & Highly unequal & 0.55 \\
\hline & South America & 21 & Equal & 0.47 \\
\hline Northern America & Northern America & 177 & Highly equal & 0.21 \\
\hline \multirow[t]{4}{*}{ Oceania } & $\begin{array}{l}\text { Australia and New } \\
\text { Zealand }\end{array}$ & 36 & Equal & 0.42 \\
\hline & Melanesia & 289 & Highly unequal & 0.58 \\
\hline & Micronesia & & No data & \\
\hline & Polynesia & & No data & \\
\hline
\end{tabular}

quality between -1 and 1 . Countries were coded as low governance quality (Low WGI $=1$ ) if WGI was smaller than -0.5 , as medium governance quality (Mid WGI $=2$ ) if WGI falls between -0.5 and 0.5 and as high governance quality (High WGI $=3$ ) if WGI is larger than 0.5 .

The Gini coefficient of response distribution across response classes was calculated for each region of the world by first placing the values for each response class in ascending order and then calculating:

$$
G=\frac{\sum_{i=1}^{n}(2 i-n-1) x_{i}}{n \sum_{i=1}^{n} x_{i}}
$$

where $x$ is an observed value, $n$ is the number of values observed and $i$ is the rank of values in ascending order.

Thresholds for the Gini categories were calculated as follows: The threshold (A) between equal and unequal distribution is the median of all Gini values calculated for sub-regions for which sufficient data points exist. The threshold between highly equal and equal distribution is the median of all Gini values smaller than A, and the threshold between highly unequal and unequal distribution is the median of all Gini values greater than A.

Recognising that the number of data points we have available in our study varies between regions and between hazard types, we tested the possibility that the diversity of responses for some hazards or regions is directly linked to the number of data points. However, we find that 
there is no clear pattern indicating that regions with more data points (i.e. response examples) have more equal distribution across the five response classes (Table 3 ).

\section{A new typology of hazard responses}

We found that within the body of case studies, examples of community-based hazard responses are diverse, ranging from forming neighbourhood committees (Lewis 2013) to building hazard-proof homes (Marfai et al. 2015). Assessment of the various hazard responses within the global dataset led to an emergent inductive categorisation into five classes according to the nature and goals of the responses (Fig. 1, Online Resource 1):

1) Individual and material wellbeing. Such responses are directed at securing basic necessities such as food, shelter and belongings, as well as livelihoods and health.

2) Relational wellbeing. These responses typically involve collective action and interactions among community members, ranging from utilising kinship networks or formal community networks to temporary evacuations or permanent relocation of entire communities.

3) Awareness (of hazards and risks). Awareness responses include monitoring (e.g. of flood levels) or taking an inventory of one's belongings, as well as those involving traditional knowledge.

4) Guidance and governance. Guidance responses relate to governance, management and other aspects of decision-making, involving actions that handle, direct, govern, or control aspects of human hazard interaction.

5) Infrastructure. These responses involve infrastructure for physical hazard defence, either based on engineering efforts (e.g. sea walls) or utilising ecological properties for protection (e.g. the replanting of hill sides to prevent mud slides).

All five classes of hazard response are utilised at a community level, across all the major types of hazards. Responses oriented to individual and material wellbeing and to relational wellbeing are the most frequently used across all hazard types (Fig. 2). In terms of the overall distribution across response classes, community-level responses to water-related hazards utilise all five response classes with similar frequencies, and there is also a relatively even distribution for earth-related hazards, apart from a low use of infrastructure responses. In contrast, responses to weather-related hazards are heavily weighted to interventions affecting individual and material wellbeing.

\section{Results}

\subsection{Responses vary between major types of hazards}

The most frequently reported hazards are drought, extreme weather, flood and storm (Table 2). Reported responses to these hazards vary across regions of the world (Table 4).

Drought The majority of responses to drought events are reported for communities in Oceania. No responses to drought are reported for Northern America. For most regions, 


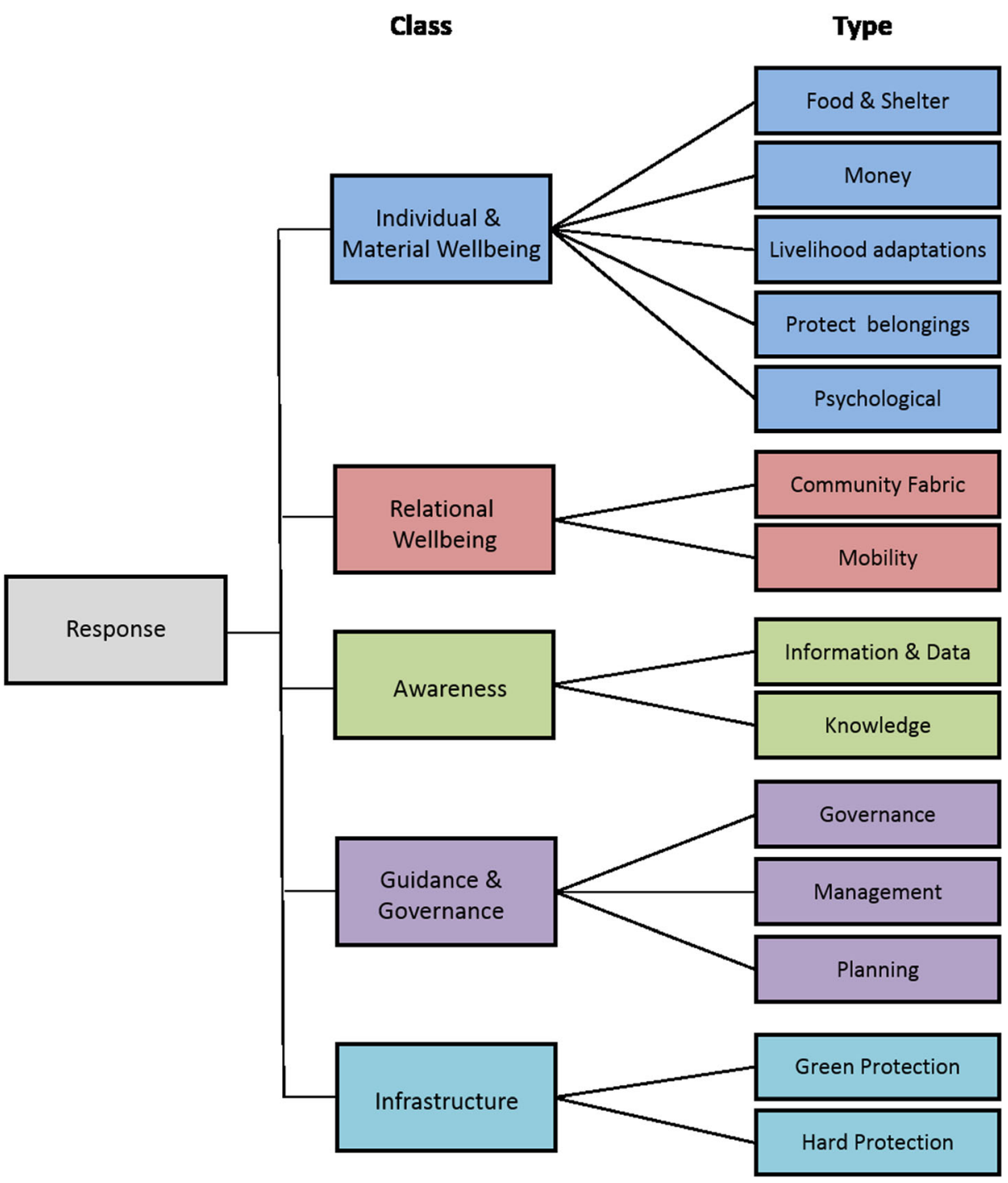

Fig. 1 Emergent inductive categorisation of various hazard responses within the global dataset into five classes according to the nature and goals of the responses

reported responses to drought fall into the category Individual and Material Wellbeing, except for examples from Europe which are evenly distributed across Individual and Material Wellbeing, Relational Wellbeing and Awareness. Not surprisingly, no infrastructure examples are reported for drought. Guidance and Governance responses are reported only from Latin America and Oceania, and constitute only a small percentage of the responses to drought in these two regions.

Floods In the case of flood events, the majority of response examples are from Asia and the fewest examples from Oceania. Although $68 \%$ of responses to flood from Africa fall into the category Individual and Material Wellbeing, and 61\% from Oceania focus on Infrastructure, 


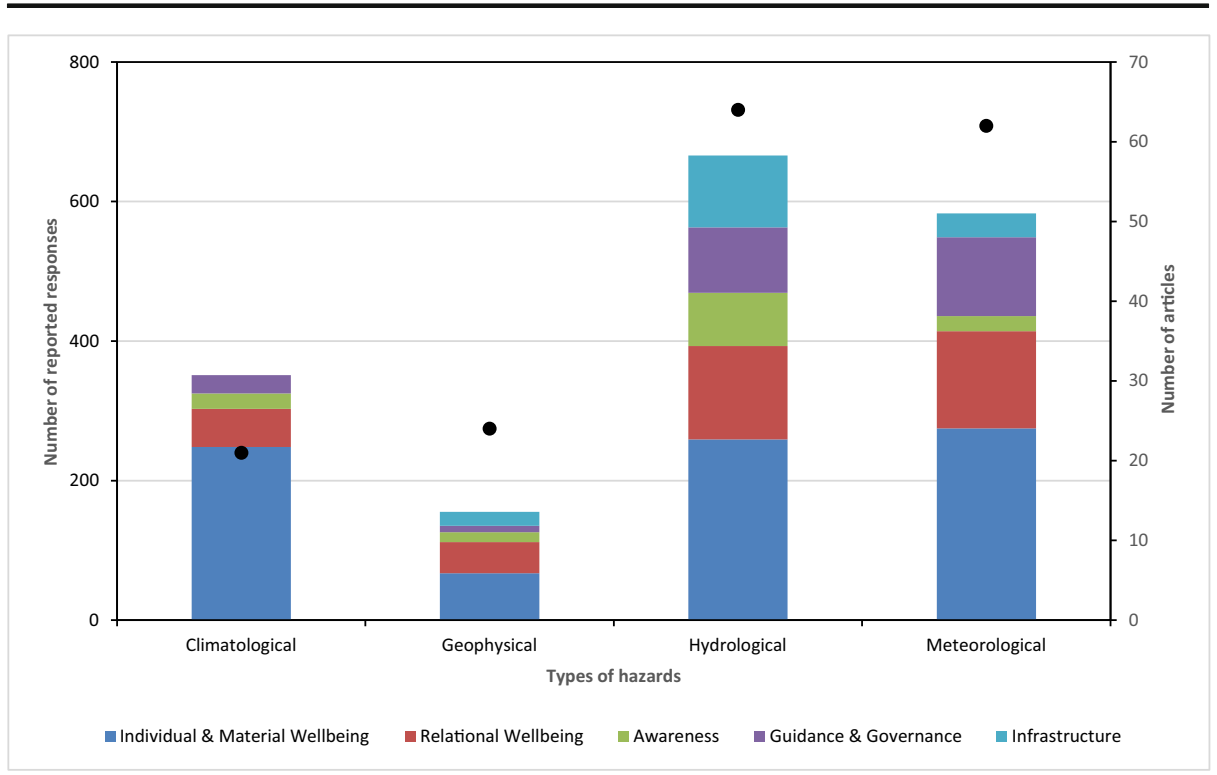

Fig. 2 All five classes of hazard response utilised at a community level, across all the major types of hazards

there seems to be a better distribution of examples across the five response classes for Asia, Europe, Latin America and Northern America.

Extreme weather This picture is somewhat different for extreme weather, with no responses being reported from Europe and Northern America and most responses reported from other regions falling into the category Individual and Material Wellbeing. The notable exception is that $46 \%$ of response examples in Asian case studies fall into Guidance and Governance. No Awareness responses are reported from any of the regions.

Storms Most of the response examples to storm are reported for Asia, Latin America and Oceania. Only very few examples are reported from Africa and Europe. In spite of the large number of response examples from Asia, no Infrastructure responses are reported for this region.

In the case of flood and drought events, response examples appear to be better distributed across the five regions and five classes of responses, at least in the sense that there are less blank fields in the tables for these hazards than for drought and extreme weather. A comparison of the Gini coefficients for the four main hazard types corroborates that, indeed, the Gini coefficients for flood and storm are lower than the coefficients for drought and extreme weather (Table 4), indicating more unequal distributions of examples across the response typology for the latter types of hazards.

\subsection{Hazard responses vary across regions of the world}

Our database reveals areas for which very little or no data is available on community responses to climate hazards (Table 3 and Fig. 3). There are not many articles reporting empirical 


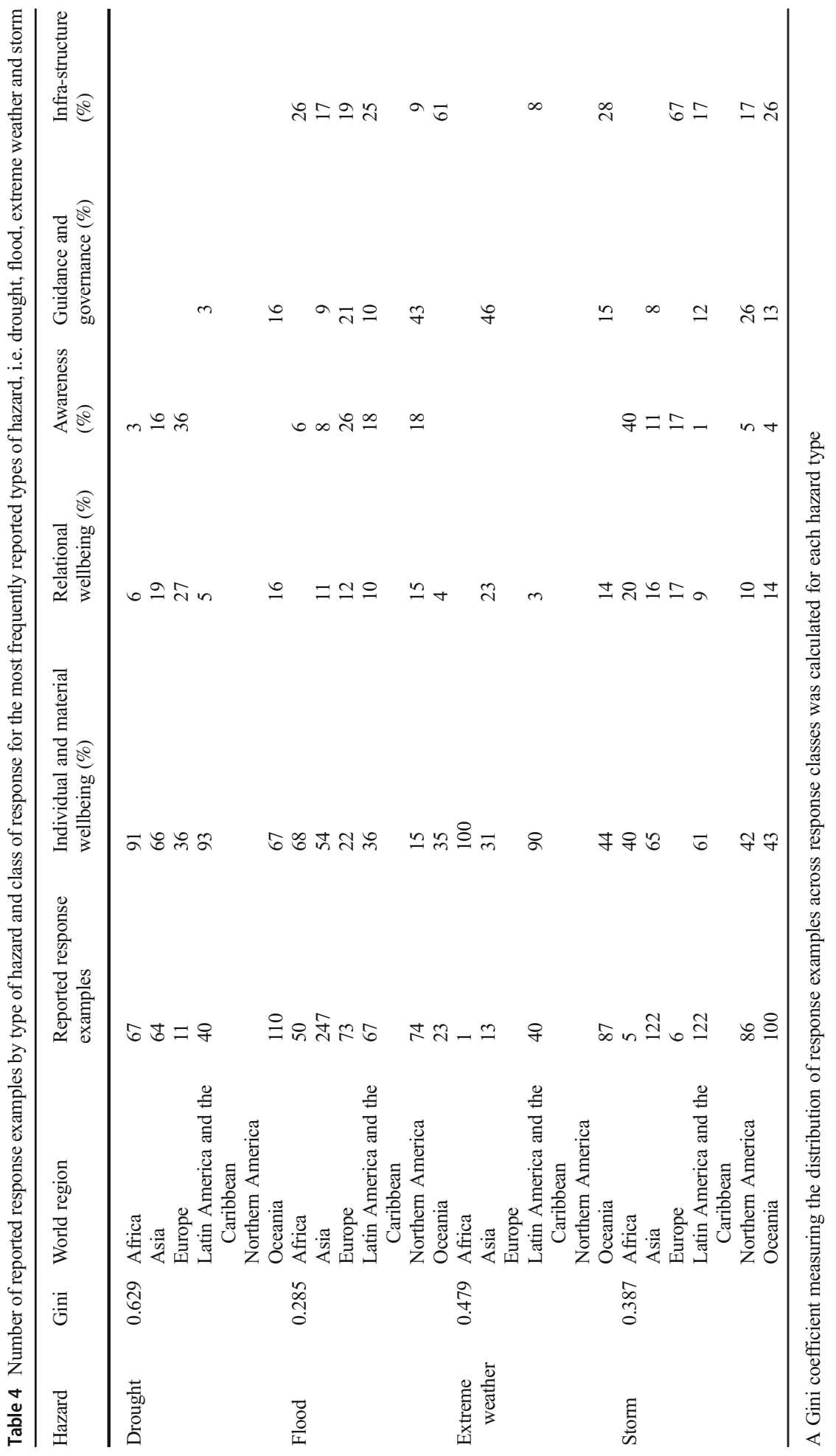


information about community-level responses in Africa, and the few that we found contain insufficient data - for Northern Africa in particular. This is striking as Africa is associated with a high frequency of drought and flood disasters (Creed 2015). The lack of data for some areas may be explained by language bias, for example Eastern Europe and North Eastern Asia, but the lack of data for Western Europe is striking. Although Asia is the region with most data points (Table 1), the data covers only three of the six sub-regions.

Concentrating on geographic areas with sufficient data points, we find the largest Gini coefficient and thus the most unequal distribution to be in East Africa (0.712), Pacific Island states (0.582) and Central America (0.552). The smallest Gini value and therefore the most equal distribution across response classes is found in Northern America (0.208), South-East Asia (0.294) and Northern Europe (0.353).

Each major region of the world has its own variations across sub-regions in terms of the diversity of the response portfolios.

In the Americas (Fig. 3), all response classes occur with significant frequency in Northern America, with emphasis on Relational Wellbeing (30\%) and Guidance and Governance (29\%) responses. In Central and South America, Individual and Material Wellbeing responses are most frequent $(67 \% ; 50 \%)$ and Guidance and Governance $(2 \% ; 0 \%)$ responses are least frequent. Comparatively, responses are fairly equally distributed in the North, and to some extent the South, compared with Central America and the Caribbean.

In Europe (Fig. 3), responses are more evenly distributed in the North than the South. Responses in the North are spread over several classes, though with a high frequency in the Guidance and Governance class (43\%). In contrast, the majority of reported responses for Southern Europe fall in the classes Awareness (49\%) and Individual and Material Wellbeing $(32 \%)$.

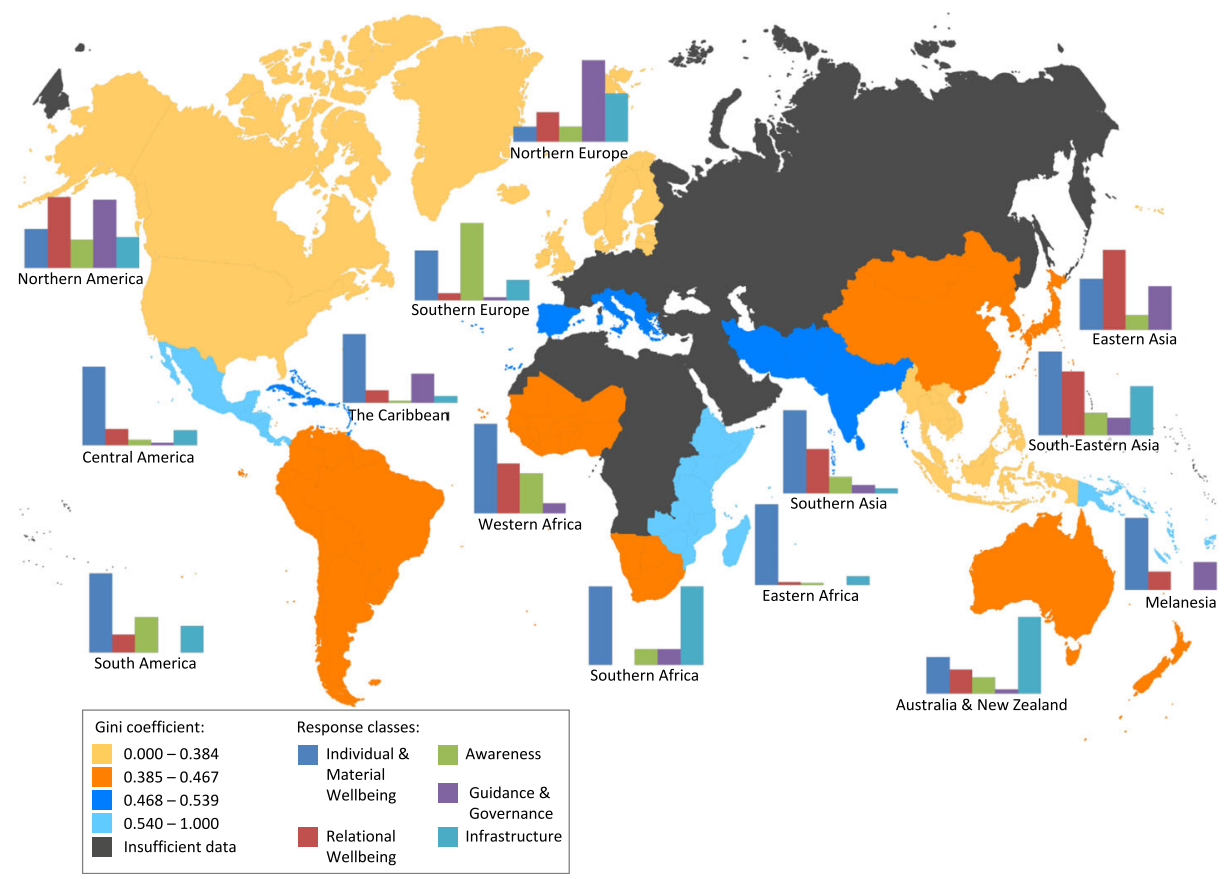

Fig. 3 Areas for which very little or no data is available on community responses to climate hazards 
In Asia (Fig. 3), all three sub-regions have the categories Individual and Material Wellbeing and Relational Wellbeing as most frequently occurring, although in Southern and SouthEastern Asia, Individual and Material Wellbeing (53\%; 35\%) is more dominant. In Southern Asia, Awareness (11\%), Guidance and Governance (5\%) and Infrastructure (3\%) responses are low; in East Asia, Infrastructure responses are absent but form the third largest group in Southeast Asia (21\%). In Asia, overall (Fig. 3), the distribution of responses across categories is least equal in Southern Asia.

In the African sub-regions for which sufficient data is available, the most frequently reported class is Individual and Material Wellbeing (Fig. 3), and indeed, in Eastern Africa, a dominant $85 \%$ of reported responses fall into this category. In Southern Africa and Western Africa, both of which have Individual and Material Wellbeing as the most frequent response (40\%), the clear difference lies in Infrastructure responses, which were a high proportion of all responses for Southern Africa (33\%) but were entirely absent in the data for Western Africa (where Awareness (23\%) and Relational Wellbeing (30\%) were relatively frequent). Overall, across the African sub-regions (Fig. 3), the distribution of responses is most unequal in Eastern Africa.

In Oceania, the response portfolio for Pacific Island states is very unequally distributed across response categories especially in comparison with the relatively even portfolio for Australia and New Zealand (Fig. 3). Only three classes of responses are reported for the former, i.e. Individual and Material Wellbeing (61\%), Relational Wellbeing (16\%) and Guidance and Governance (24\%), while for the latter, a significant level of responses are reported for all categories, with Infrastructure being the most frequent (49\%); this was followed by Individual and Material Wellbeing (23\%) and Relational Wellbeing (15\%).

\subsection{Hazard responses correlate between high- and low-income economies}

To investigate why community-level hazard responses vary across areas of the world, we examined the influence of national economic and governance indicators on the relative frequencies of reported responses for each class of response.

We first stratified responses by gross national income (GNI) into three groupings based on the classification used by the World Bank in 2017 (https://data.worldbank.org): low (< USD 4036), middle (USD 4036 to 12,475) and high (> USD 12,475).

The Gini coefficient was used to measure the equality of distribution of reported responses across the five categories for each of the three income groupings. We find that for countries with low-income economies, responses are spread unevenly across the five response classes with a Gini coefficient of 0.53 , while middle-income countries have a more even distribution across response categories (Gini $=0.37$ ), and this is even more so for high-income countries $($ Gini $=0.07)$. Overall, this analysis shows that on a national basis, the higher the income level, the greater the equality in the distribution of response classes utilised at the community level.

Looking at results for each response class, Individual and Material Wellbeing responses dominate in low-income countries $(60 \%)$, while the relative frequency of this response class decreases to $46 \%$ for middle-income countries, and high-income countries have an even lower frequency (25\%; Fig. 4a). The reverse occurs for Awareness and Infrastructure responses, for which the frequencies show clear upward trends with income. Awareness responses remain relatively constant for low- and middle-income countries (8\% of all response examples for low-income countries, $6 \%$ of responses for middle-income countries), but increase substantially for high-income countries $(20 \%)$. In contrast to the strong trends across income levels 
(a) Frequency of Response Type by GNI

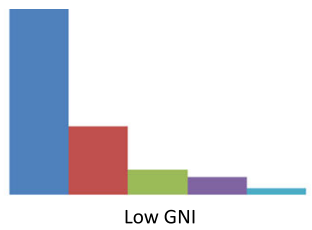

Infrastructure
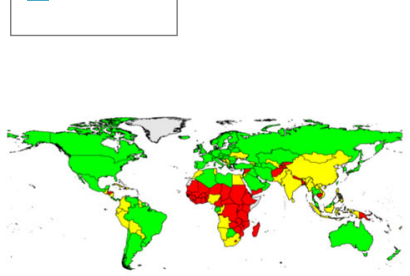

Countries by GNI
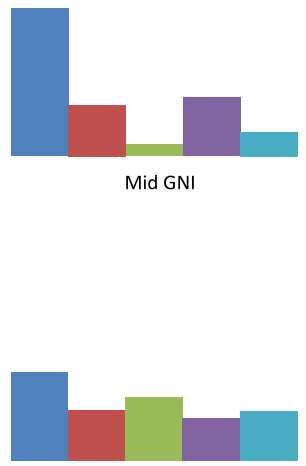

High GNI (b) Frequency of Response Type by WGI

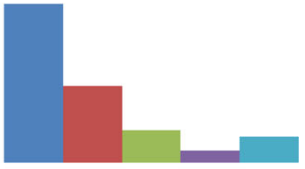

Low WGI
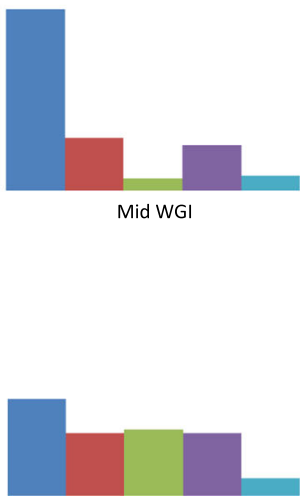

High WGI

Countries by WGI $\square$ Low Mid $\square$ High

Fig. 4 a Frequency of response type by GNI. b Frequency of response type by WGI

noted for the above three response classes, Relational Wellbeing is relatively constant in frequency across all income categories (23\% of all response events for low-income countries, $19 \%$ for middle-income countries and $19 \%$ for high-income countries). Finally, there is no clear trend for Guidance and Governance responses in relation to GNI, with an increase in frequency from low $(6 \%)$ to middle-income countries $(21 \%)$ but then a decrease for highincome countries $(19 \%)$.

To further explain these variations, it should be recalled that, while most of this analysis is based on the five aggregate hazard response classes, each of these has constituent components (Online Resource 2). Focusing on Awareness, for example, for the low-income group of countries, $98 \%$ of responses of that class were of three types, $46 \%$ linked to local knowledge, followed by early warning (27\%) and information sharing (25\%). For high-income countries, on the other hand, Awareness responses are much more diverse, with the most frequent four types comprising a lower $69 \%$ of responses: accessing information (29\%), local knowledge (17\%), early warning (12\%) and technical expertise (11\%). Further, several of the latter types are likely costlier (and thus more available for high-income countries) than the sharing of information among community members and the use of local knowledge.

A similar disaggregation of responses leads to an understanding of why Infrastructure is the response class most clearly and consistently rising in frequency with income level. The majority $(90 \%)$ of responses in this class involve use of 'hard' or engineering type interventions (e.g. structural changes to hazard-proof buildings or construction of sea walls and other defensive structures). These kinds of responses are likely costlier than green interventions, such as mangrove maintenance or restoration, and living shoreline initiatives, of which there are few examples in the data across all income categories. 


\subsection{Hazard responses correlate with governance quality}

The lack of a relationship between the frequency of Guidance and Governance responses and GNI, noted above, suggests that responses in this class may be linked to other factors besides income. A logical possibility is a linkage to the overall quality of national governance. Accordingly, we examined the influence on response class frequencies of the aggregated governance index (WGI), particularly to determine whether the quality of governance is linked to the frequency of Guidance and Governance responses. Indeed, that frequency consistently increases with the aggregate index, which suggests that there is an association between the quality of governance of a country and the frequency of Guidance and Governance responses.

In fact, Guidance and Governance is the only response class to behave in this way relative to the governance index. The frequency of Relational Wellbeing responses moves in the opposite direction, decreasing from $26 \%$ for countries with a low WGI to $19 \%$ for countries with a high WGI. Individual and Material Wellbeing responses comprise $46 \%$ of reported responses for countries with a low WGI rising to $58 \%$ for countries with a medium WGI (Fig. 4b), but the frequency drops to $25 \%$ for high WGI countries. This non-monotonic behaviour is also found for other response classes. Thus, the WGI provides predictive capability for Guidance and Governance responses but not for other response classes.

\section{Global implications: response ability}

The goal of this paper has been to provide a better understanding of the choices made at a local community level regarding responses to a range of climate-related hazards. Using a standard hazard classification scheme, focused on those potentially climate-related, we developed a global database of community-level responses to hazards. It is well established that the local scale is of crucial importance in the context of climate change adaptation (Charles 2012), yet discussions of how people in local communities should respond to climate change are often generic in nature (i.e. not place specific) or focus on individual case studies. Our global overview confirms that that there are many ways local communities can and are responding to the effects of climate change both short-term and long-term.

The database developed here enabled creation of a new typology of hazard responsesgrouped into five major response classes (Individual and material wellbeing; Relational wellbeing; Awareness (of hazards and risks); Guidance and governance; Infrastructure). Although various typologies have been developed of adaptation actions (Burton et al. 2000; Smit and Skinner 2002; Biagini et al. 2014), there are few cross-scale analyses of the full range of local interventions, based on empirical data from activities on the ground (Biagini et al. 2014). Our community-based typology of hazard responses fills this gap, providing an evidence-based framework to guide climate change adaptation strategies both on the level of local communities and municipalities, as well as on national and global levels. In particular, this analysis places climate responses fully within the framework of existing hazard responses more broadly, integrated within the hazard response typology and its set of five response classes.

The frequency of occurrence of these response classes, and the resulting 'response portfolio', varied across the four major climate-related hazards (drought, extreme weather, floods and storms). The frequencies of the five response classes also varied across the regions and subregions of the world. 
A key explanation for the latter geographical variations in hazard responses lies in national income levels (GNI). Collectively, communities in all regions utilise all five classes of responses to hazards, but developing countries have less diverse response portfolios than developed countries. This is prominent with the Infrastructure response class; while its frequency is low across all income categories, it is notably lowest for low-income countries. This likely reflects the relatively high cost of hard infrastructure responses. In a similar manner, the low frequency of Awareness responses in low-income countries can be explained by noting that many Awareness responses involve expensive monitoring systems. These results suggests that more research is needed to investigate how climate responses in poorer countries might benefit from more cost-effective strategies, such as (1) use of green infrastructure, which may be less costly then hard infrastructure and more easily implemented at the local community level, and (2) use of local knowledge, which may be effective especially where expensive monitoring systems are not feasible.

While consideration of national income levels explained how several of the hazard response categories varied across countries, it did not explain observed variations for the Guidance and Governance class. Instead, this category was influenced most clearly by the overall quality of national governance. We found that as a result, implementation of local-level hazard policy and planning responses is less frequent in countries characterised by overall low governance quality. This has implications for the capability of nations to engage in climate adaptation responses, and again highlights the need for more research to understand how communities in a range of countries can improve planning and decision-making around hazard responses.

The results presented in this paper depend on the validity of the methodology. Since the analysis is based on a global compilation of peer-reviewed articles, the hazard and response events analysed here are filtered through the lenses of the authors writing the articles. Thus, it is possible that the overall set of examples may reflect not only the actual occurrence of events, but also, or alternatively, the priorities of the authors whose articles were included in the compilation. For example, it could be hypothesised that, if there is more interest (among those writing articles) in the wellbeing of individuals in poorer countries following disasters, that could explain why that particular response class is dominant in certain regions. However, in the absence of any alternative global database of community-based hazard response actions, the method used in this paper provides initial guidance on response classes and their prevalence internationally.

The methodology of this paper, i.e. the systematic review of articles and analysis of the resulting data, also reveals significant gaps in the evidence-based literature on climate-related hazards and hazard responses. Notably, for example, (1) there is a lack of empirical information from Africa, particularly Northern Africa and middle Africa; (2) despite a large number of articles for Asia, there is no data for North-Eastern Asia and Western Asia; (3) for Europe, there were no articles from Eastern Europe and little data for Western Europe and (4) few articles cover specific hazard responses in Oceania, and although these yielded a good number of response examples, there is no data at all for Micronesia nor Polynesia. Furthermore, our analysis of how responses vary across particular major hazard types revealed that there is no information about responses to drought and extreme weather from Northern America and no responses to extreme weather from Europe.

Understanding what kinds of responses are implemented in different regions of the world, and the factors that influence the nature of these responses enables an informed prioritisation of climate change adaptation interventions by governments and funding agencies, within suitable governance systems, to increase resilience at the local level (Charles 2004; Armitage et al. 
2017). As decisions concerning responses to climate change become increasingly crucial on a global basis, it will be important to address any information gaps, to improve our understanding of hazard response portfolios around the world.

Acknowledgements This research was supported by Saint Mary's University and the Marine Environmental Observation Prediction and Response (MEOPAR) Network of Centres of Excellence. Additional financial support is acknowledged from the Natural Sciences and Engineering Research Council of Canada (NSERC) and the Social Sciences and Humanities Research Council (SSHRC).

Open Access This article is distributed under the terms of the Creative Commons Attribution 4.0 International License (http://creativecommons.org/licenses/by/4.0/), which permits unrestricted use, distribution, and reproduction in any medium, provided you give appropriate credit to the original author(s) and the source, provide a link to the Creative Commons license, and indicate if changes were made.

Publisher's Note Springer Nature remains neutral with regard to jurisdictional claims in published maps and institutional affiliations.

\section{References}

Adger WN, Barnett J, Brown K, Marshall N, O'Brien K (2013) Cultural dimensions of climate change impacts and adaptation. Nat Clim Chang 3:112-117

Alam K, Rahman MH (2014) Women in natural disasters: a case study from southern coastal region of Bangladesh. Int J Disaster Risk Reduct 8:68-82

Armitage D, Berkes F, Charles A (2017) Governing the coastal commons: communities, resilience and transformation. Routledge, New York

Berkes F, Ross H (2013) Community resilience: toward an integrated approach. Soc Nat Resour 26:5-20

Biagini B, Bierbaum R, Stults M, Dobardzic S, McNeeley SM (2014) A typology of adaptation actions: a global look at climate adaptation actions financed through the Global Environment Facility. Glob Env Change 25: 97-108

Burton I, Klein RJ, Wandel J (2000) An anatomy of adaptation to climate change and variability. Clim Chang 45(1):223-251

Charles, A. (2004) Sustainability and resilience in natural resource systems: policy directions and management institutions. In: Lysenko G. et al (eds) Encyclopaedia of life support systems. http://www.eolss.net. Accessed 22 November 2017

Charles A (2012) People, oceans and scale: governance, livelihoods and climate change adaptation in marine social-ecological systems. Curr Opin Env Sust 4:351-357

CRED (2011) EM-DAT. The OFDA/CRED international disaster database. Université Catholique de Louvain, Brussels www.emdat.be. Accessed 22 Nov 2017

CRED (2015) The human cost of weather-related disasters 1995-2015. UNISDR, Geneva

Cutter S, Osman-Elasha B, Campbell J et al (2012) Managing the risks from climate extremes at the local level. In: Field $\mathrm{C}$ et al (eds) Managing the risks of extreme events and disasters to advance climate change adaptation. Cambridge University Press, Cambridge, pp 291-338

Cutter SL, Ismail-Zadeh A, Alcántara-Ayala I, Altan O, Baker DN, Briceño S, Gupta H, Holloway A, Johnston D, McBean GA, Ogawa Y, Paton D, Porio E, Silbereisen RK, Takeuchi K, Valsecchi GB, Vogel C, Wu G (2015) Pool knowledge to stem losses from disasters. Nature 522:277-279

Day S, Fearnley CA (2015) Classification of mitigation strategies for natural hazards: implications for the understanding of interactions between mitigation strategies. Nat Hazards 79:1219-1238

Dekens J (2007) Local knowledge for disaster preparedness: a literature review. International Centre for Integrated Mountain Development, Kathmandu

Fekete A, Damm M, Birkmann J (2010) Scales as a challenge for vulnerability assessment. Nat Hazards 55:729747

Ferdinand I, O’Brien G, O’Keefe P, Jayawickrama J (2012) The double bind of poverty and community disaster risk reduction: a case study from the Caribbean. Int J Disaster Risk Reduct 2:84-94

Gariano SL, Guzzetti F (2016) Landslides in a changing climate. Earth Sci Rev 162:227-252

Gough D, Oliver S, Thomas J (2012) An introduction to systematic reviews. Sage, London 
Hallegatte S, Green C, Nicholls RJ, Corfee-Morlot J (2013) Future flood losses in major coastal cities. Nat Clim Chang 3:802-806

Henly-Shepard S, Anderson C, Burnett K et al (2015) Quantifying household social resilience: a place-based approach in a rapidly transforming community. Nat Hazards 75:343-363

Hirabayashi Y, Mahendran R, Koirala S, Konoshima L, Yamazaki D, Watanabe S, Kim H, Kanae S (2013) Global flood risk under climate change. Nat Clim Chang 3:816-821

IPCC (2014a) Climate Change 2014: synthesis report. IPCC, Geneva

IPCC (2014b) Climate Change 2014: impacts, adaptation, and vulnerability. Part B: regional aspects. In: Contribution of Working Group II to the Fifth Assessment Report of the Intergovernmental Panel on Climate Change. Cambridge University Press, Cambridge

Jongman B, Ward PJ, Aerts JCJH (2012) Global exposure to river and coastal flooding: long term trends and changes. Glob Environ Chang 22:823-835

Kaufmann A, Kraay A (2017) Worldwide governance indicators. http://info.worldbank.org/governance/wgi/. Accessed 22 Nov 2017

Krippendorff K (2013) Content analysis: an introduction to its methodology. Sage, London

Lei Y, Wang J, Yue Y, Zhou H, Yin W (2014) Rethinking the relationships of vulnerability, resilience, and adaptation from a disaster risk perspective. Nat Hazards 70:609-627

Lewis J (2013) Some realities of resilience: an updated case study of storms and flooding at Chiswell, Dorset. Disaster Prev Manag 22:300-331

Marfai MA, Sekaranom AB, Ward P (2015) Community responses and adaptation strategies toward flood hazard in Jakarta, Indonesia. Nat Hazards 75:1127-1144 The World Bank (2017) Country Classification. https://datahelpdesk.worldbank.org/knowledgebase/topics/19280-country-classification. Accessed 22 November 2017

McNamara KE, Prasad SS (2014) Coping with extreme weather: communities in Fiji and Vanuatu share their experiences and knowledge. Clim Chang 123:121-132

Prabhakar SVRK, Srinivasan A, Shaw R (2009) Climate change and local level disaster reduction planning: need, opportunities and challenges. Mitigation Adapt Strateg Glob Chang 14:7-33

Reid H, Huq S (2014) Mainstreaming community-based adaptation into national and local planning. Clim Dev 6(4):291-292

Reid H, Alam M, Berger R, Cannon T, Huq S, Milligan A (2009) Community- based adaptation to climate change: an overview. PLA 60:11-38

Rojas Blanco AV (2006) Local initiatives and adaptation to climate change. Disasters 30:140-147

Savo V, Morton C, Lepofsky D (2017) Impacts of climate change for coastal fishers and implications for fisheries. Fish Fish 18(5):877-889

Seneviratne SI, Nicholls N, Easterling D, Goodess CM, Kanae S, Kossin J, Luo Y, Marengo J, McInnes K, Rahimi M, Reichstein M (2012) Changes in climate extremes and their impacts on the natural physical environment. In: Field CB, Barros V, Stocker TF, Dahe Q (eds) Managing the risks of extreme events and disasters to advance climate change adaptation: special report of the intergovernmental panel on climate change. Cambridge University Press, Cambridge and New York, pp 109-230

Smit B, Skinner MW (2002) Adaptation options in agriculture to climate change: a typology. Mitig Adapt Strateg Glob Chang 7(1):85-114

Strauss A, Corbin J (1998) Basics of qualitative research: techniques and procedures for developing grounded theory. Sage, Los Angeles

Trenberth KE, Dai A, van der Schrier G, Jones PD, Barichivich J, Briffa KR, Sheffield J (2014) Global warming and changes in drought. Nat Clim Chang 4:17-22

UNDP (2015) Human Development Report 2015: work for human development. http://hdr.undp. org/sites/default/files/2015_human_development_report.pdf. Accessed 22 Nov 2017 